\title{
Transvection in the Ultrabithorax Domain of the Bithorax Complex of Drosophila melanogaster
}

\author{
David Mathog \\ Centro de Biologia Molecular del C.S.I.C., Facultad de Ciencias, Universidad Autónoma de Madrid, Canto Blanco, Madrid 28049, \\ Spain, and 'Division of Biology 156-29, California Institute of Technology, Pasadena, California 91125 \\ Manuscript received October 2, 1989 \\ Accepted for publication February 28, 1990
}

\begin{abstract}
The phenotypes of several heterozygous combinations of mutations which map within the Ultrabithorax gene of Drosophila melanogaster are modulated by the extent of somatic homologous chromosome pairing, an effect known as transvection. One can discriminate between otherwise phenotypically similar mutations via their transvection behavior. This suggested the existence of previously undetected intragenic functional units. A collection of mutations has been classified into "transvection groups" (in analogy to complementation groups) on the basis of transvection tests with bithorax ${ }^{34}$, postbithorax ${ }^{2}$, and Contrabithorax ${ }^{l}$ Ultrabithorax $x^{I}$. The conditions necessary for each transvection effect were determined from these transvection groups. The bithorax ${ }^{34}$ mutation only transvects with Ultrabithorax mutations with a contiguous Ultrabithorax transcriptional unit. In contrast, postbithorax ${ }^{2}$ transvection requires the distal part of the bithoraxoid region. As expected, Ultrabithorax mutations do not transvect with Contrabithorax ${ }^{l}$ Ultrabithorax ${ }^{I}$. However, it appears that this cross activation is not mediated solely through one of the known regulatory regions as mutations in these regions do not consistently block the response.
\end{abstract}

$\mathrm{T}$ HE Ultrabithorax domain of the bithorax complex of Drosophila melanogaster contains a large and complicated gene primarily required for the correct development of parasegments 5 and 6 (LEWIS 1963; SANChez-HerRero et al. 1985; MarTinezARIAS and LAWRENCE 1985). In an animal homozygous for an Ultrabithorax (Ubx) mutation, both parasegments are transformed into parasegment 4 . There are several other types of mutant syndromes associated with lesions in the Ultrabithorax domain, each affecting only part of the $U b x$ type transformation (LewIS 1955, 1981). The phenotypes of these mutations were first characterized in the adult cuticle. The anterobithorax and bithorax ( $a b x$ and $b x)$ mutations primarily transform the anterior third thoracic segment (T3a). bithoraxoid ( $b x d$ ) lesions alter both the posterior third thoracic segment and the anterior first abdominal segments (T3p, Ala). postbithorax (pbx) mutations primarily affect the development of T3p. Contrabithorax $(C b x)$ mutations also map within the Ultrabithorax domain. $C b x$ mutations partially transform the second thoracic segment, producing patterns typical of the third thoracic segment.

Ultrabithorax domain mutations have been mapped both genetically and molecularly (Figure 1) (LEwIS 1955, 1978; BENDER et al. 1983). Ubx mutations lie within a $75 \mathrm{~kb}$ protein coding transcription unit. Also located within this region are the $C b x^{I}$ insertion into

\footnotetext{
' Current address.
}

the second intron, and all of the $a b x$ and $b x$ lesions, which are in the third and final intron (BENDER et al. 1983; Hogness et al. 1985; PEIFER and BENDER 1986). A second transcribed region, approximately $30 \mathrm{~kb}$ long and immediately upstream from the $U b x$ transcription unit, contains the sites of all $b x d$ and $p b x$ lesions. The relation between $U b x$ mutations and the phenotypes that result from them is clear; in most cases the long transcription unit is broken or particular exons are affected, thus eliminating one or more of the Ubx family of proteins (WEINZIERL et al. 1987; Peifer, Karch and Bender 1988). How the non- $U b x$ lesions cause their associated phenotypes is not yet understood. Each of these syndromes affects a different part of the animal and alters the spatial and quantitative expression of $U b x$ protein, but does not disrupt the protein coding regions of the gene (LEWIS 1963; BEACHY et al. 1985; WHITE and WILCOX 1985; White and AKam 1985; Bender et al. 1983). Furthermore, mutations of different types can complement each other (LEwIS 1963). Clearly these non-Ubx mutations alter the regulation of the Ultrabithorax domain and many or all of them are thought to be lesions of normal regulatory regions of that gene (BEACHy et al. 1985; Hogness et al. 1985; PeIfer and BENDER 1986).

In Drosophila, interphase somatic chromosomes are normally synapsed (METZ 1916), but certain chromosome rearrangements disrupt this pairing. Lewis $(1954,1955,1982)$ discovered that the degree of 


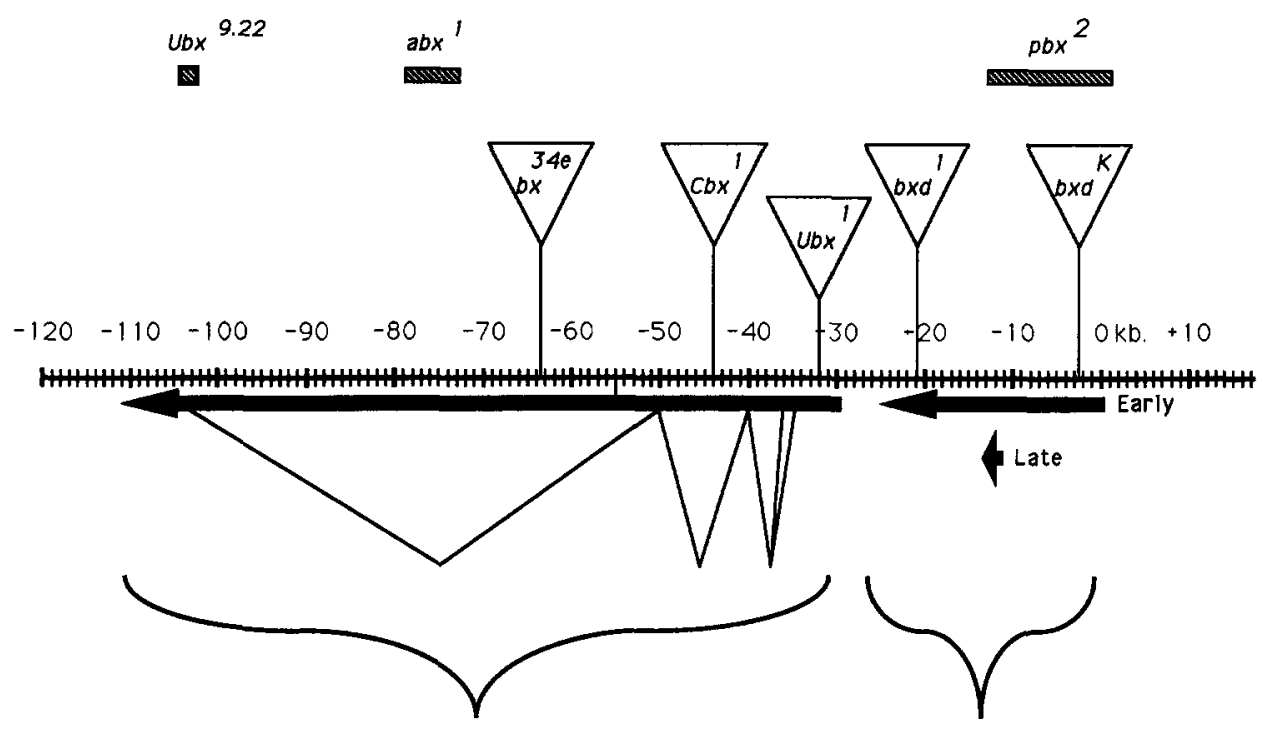

FiguRE 1.-A schematic overview of the organization of the Ultrabithorax domain illustrating its two transcription units and the locations of several mutations. Hatched rectangles represent DNA deletions, inverted triangles are insertion elements, and large arrows depict transcription units. Donor and acceptor sites for $U b x$ mRNAs are also shown. The complex splicing pattern for $b x d$ is not shown. Data is from BENDER $e t$ al. (1983) and HogNess et al. (1985).

UItrabithorax

complementation of certain Ultrabithorax domain genotypes is modulated by the extent of this pairing. $\mathrm{He}$ named pairing dependent complementation "transvection" and the transvection suppressing chromosome rearrangements "TSRs." Subsequently, the term transvection was generalized to include any situation where the paired phenotype differs from the unpaired for an otherwise similar genotype (GELBART and WU 1982).

Many of the regulatory mutations of the Ultrabithorax domain participate in transvecting genotypes. Transvection may result when regulatory regions, which normally act over long distances in cis, occasionally "miss" and cross-regulate the closely paired homologous allele (LEwIS 1954). It is common to classify mutations into complementation groups. In this paper this approach is extended by using transvection tests, rather than complementation tests, to define the groups. Transvection is assayed for $b x^{34 e}$, $p b x^{2}$, and $C b x^{1} U b x^{l}$ vs. a large number of other Ultrabithorax domain mutations. Since most of the mutations utilized have been mapped at the molecular level, such groups indicate which parts of the Ultrabithorax domain are required for the different transvection effects tested.

\section{MATERIALS AND METHODS}

Crosses were performed at $25^{\circ}$ in shell vials. J. Casanova who also isolated $b x d^{M X I}$, constructed the chromosome $U b x^{9.22} C 1$ by recombination. I. VERNOS and E. MARTIN characterized $b x d^{M X I}$. All other stocks are described in LINDSLEY and GRELL 1968; LEWIS 1978; KERRIDGE and MORATA 1982; BENDER et al. 1983; AKAM et al. 1985; BENDER et al. 1985; KARCH et al. 1985; SANCHEZ-HERRERO et al. 1985; LINDSLEY and ZIMM 1987; WEINZIERL et al. 1987; or Casanova, Sanchez-Herrero and Morata 1988. Chromosome rearrangements and new $U b x$ alleles were induced with X-rays $(100 \mathrm{kV}, 15 \mathrm{~mA}, 2$-mm aluminum filter $)$, typi-

\section{bithoraxold}

cally with a dose of $3000 \mathrm{R}$. Cytology was determined from conventional lactic acid/orcein polytene chromosome squashes (LEFEVRE 1976).

The phenotypes in tests of $b x^{34 e}, p b x^{2}$ and $C b x^{I} U b x^{1}$ transvection were assayed directly under the dissecting microscope. Numerical values were assigned for each phenotype.

For the $p b x$ transformation of posterior haltere to posterior wing: $0=$ wild type; 1 = slight enlargement of posterior haltere; 2 as 1 , but including posterior marginal wing bristles; $3=$ as 2 , but including some wing blade; $4=$ sufficient wing blade so that the appendage is longer than it is wide; $\mathbf{5}=$ complete transformation.

For the $b x^{34 e}$ transformation producing notum in T3a: 0 = no transformation; 1 = cuticle visible, but no bristles; $2=$ $<5$ bristles per side; $3=<25$ bristles per side; $4=<50$ bristles per side; $5=$ maximal transformation (about 60 bristles per side).

For the transformation of wing to haltere associated with $C b x^{l} U b x^{1}$ transvection (which is somewhat variable even within a given cross): $0=$ wild type wing; $1=$ intermediate phenotype (differs from 0 in having at least a reduction of the alula, may also have spread and/or slightly warped wings, but never so extreme as $\left.C b x^{I} U b x^{1} /+\right) ; 2=$ as $C b x^{1} U b x^{I} /+$ (extreme alula reduction, wings strongly warped).

For the purpose of these experiments, designed to map regions involved in transvection, these measurements were thought to be sufficiently precise. It is possible that a very weak complementation of $b x^{34 e}$ or $p b x^{2}$ would have been scored as a 5 (rather than 4 ).

The definition of the transvection effect used here is general and can be applied to all transvection effects so far described. It is easiest to present this definition symbolically. Let $\mathbf{a}$ and $\mathbf{b}$ represent two combinations of alleles for $\mathbf{a}$ chromosome and let $(\mathbf{a} / \mathbf{b})$ be the heterozygous genotype. A genotype can be in one of two states, written $/ /(\mathbf{a} / \mathbf{b})$ and $\Lambda(\mathbf{a} / \mathbf{b})$, and indicating when the two chromosomes are completely paired and when they are completely unpaired. A particular phenotype of a given genotype is written $P(\mathbf{a} / \mathbf{b})$. $T(\mathbf{a}, \mathbf{b})$ is the result of the transvection test for $\mathbf{a}$ and $\mathbf{b}$.

$T(\mathbf{a}, \mathbf{b})$ is positive when $P(/ /(\mathbf{a} / \mathbf{b}) \neq P(\Lambda(\mathbf{a} / \mathbf{b}))$.

$T(\mathbf{a}, \mathbf{b})$ is negative when all of the following are true:

$P(/ /(\mathbf{a} / \mathbf{b}))=P(\wedge(\mathbf{a} / \mathbf{b})) ;$ 
$/ /(\mathbf{a} / \mathbf{b})$ and $\Lambda(\mathbf{a} / \mathbf{b})$ can both be demonstrated;

$P(\mathbf{a} / \mathbf{b}) \neq$ one or more of $P(\mathbf{a} /+), P(+/ \mathbf{b}), P(\Lambda(\mathbf{a} /+))$, or $P(\Lambda(+/ \mathbf{b}))$

Otherwise, $\mathbf{T}(\mathbf{a}, \mathbf{b})$ is undefined.

Applying the preceding tests in the real world requires some approximations. In practice $P(/ /(\mathbf{a} / \mathbf{b}))$ is replaced by $P(\mathbf{a} / \mathbf{b})$, while $P(\Lambda(\mathbf{a} / \mathbf{b}))$ is replaced by $P(R(\mathbf{a}) / \mathbf{b})$, where $R()$ is the symbol for a TSR (LEwIS 1954). It must be emphasized that this substitution greatly complicates the interpretations of observed phenotypes since $/ /(\mathbf{a} / \mathbf{b})$ and $\Lambda(\mathbf{a} / \mathbf{b})$ represent completely nonoverlapping states whereas $(\mathbf{a} / \mathbf{b})$ and $(\mathbf{R}(\mathbf{a}) /$ b) correspond only approximately to these basis states. In particular, if b contains a breakpoint mutation, then the associated rearrangement will generally have some TSR properties. In this case, $(\mathbf{a} / \mathbf{b})$ can be anything from wholly $/ /(\mathbf{a} / \mathbf{b})$ to wholly $\Lambda(\mathbf{a} / \mathbf{b})$, depending on the strength of the TSR. Nevertheless, the transvection test will still be determinate as long as $(\mathbf{a} / \mathbf{b})$ contains a detectable level of the state $/ /(\mathbf{a} / \mathbf{b})$.

The following genetic test can often be used to infer the existence of $/ /(\mathbf{a} / \mathbf{b})$ : if there exists a point or pseudopoint mutation $\mathbf{b}^{t}$ such that $T\left(\mathbf{b} / \mathbf{b}^{t}\right)$ is positive, and $\mathbf{a}$ is also a point or pseudopoint mutation, then $/ /(\mathbf{a} / \mathbf{b})$ exists and is present to some extent in $(\mathbf{a} / \mathbf{b})$. This test does not say that all of the DNA in $(\mathbf{a} / \mathbf{b})$ is paired, only that it is paired somewhere within the gene. In particular, if $\mathbf{b}$ has a breakpoint which lies between $\mathbf{b}^{\mathbf{t}}$ and $\mathbf{a}$, then $(\mathbf{a} / \mathbf{b})$ may not be paired in the vicinity of a. Such crosses are still useful because their phenotype tells us if the region which is paired is sufficient for transvection of $(\mathbf{a} / \mathbf{b})$. In the present work $\mathbf{a}$ is $p b x^{2}, b x^{34 e}$, or $C b x^{l} U b x^{l}$. Since these are all pseudopoint mutations, if $T(\mathbf{a} / \mathbf{b})$ is positive with one of the three, then $/ /(\mathbf{a} / \mathbf{b})$ exists for all three $a$. If the other conditions (existence of the unpaired state and transvecting phenotype detectable) are satisfied, then $T(\mathbf{a} / \mathbf{b})$ is negative when $P(\mathbf{a} / \mathbf{b})=P(R(\mathbf{a}) / \mathbf{b})$. Typically, $\Lambda(\mathbf{a} / \mathbf{b})$ can be guaranteed by choosing a strong TSR for $(R(\mathbf{a}) / \mathbf{b})$. In the present work, the only case where $T(\mathbf{a}, \mathbf{b})$ is invariably undefined results from a failure to detect a phenotype. This occurs for $\mathbf{a}=b x^{34 e}$ and $\mathbf{b}=b x d$ or $p b x$, where $P(\mathbf{a} / \mathbf{b})=P(\mathbf{a} /+)=P(+/ \mathbf{b})=P(\mathbf{a} / R(+))=P(R(+) / \mathbf{b})$.

One unwieldy, but unavoidable, consequence of a complete definition of the transvection test is that $T(\mathbf{a}, \mathbf{b})$ has three possible values. These will be written as "transvection positive, negative, or undefined." Although awkward, this nomenclature avoids even worse problems which arise when the negation of "transvect" is not necessarily equivalent to "does not transvect." By using this construction, it should always be clear that "not transvection positive" is the same as "transvection negative or undefined."

\section{RESULTS}

A brief description of the three different transvection effects analyzed are presented here as an aid to the reader. The first effect is complementation of $p b x^{2}$. When heterozygous with pseudopoint or point mutations of $U b x$ (for example, $U b x^{I}$ ), the $p b x^{2}$ phenotype is almost completely complemented. However, in the presence of a TSR, the same genotype produces a strong transformation of T3p to T2p (LEwIS 1982). The second effect is complementation of a part of the $b x^{34 e}$ phenotype. Flies which are $b x^{34 e} / U b x^{1}$ do not have a T3a to T2a notal transformation; with the addition of a TSR, the notum is strongly transformed (LEWIS 1954). The last effect is the transformation produced by the double mutant chromosome $C b x^{1} U b x^{1}$, which induces a weak $C b x$ transformation of wing to haltere only when paired with a normal chromosome (LEwIS 1955). The numerical scales used to describe these phenotypes are described in MATERIALS AND METHoDs.

In order to produce a transvection group, in analogy to a complementation group, it is essential to consider the exact definition of the transvection test (see MATERIALS AND METHODS). In particular, it is essential to remember that the result of a transvection test can be positive, negative, or undefined. A secondary genetic test is frequently invoked in this work to demonstrate that two chromosomes are capable of pairing, and thus to distinguish between transvection negative and transvection undefined results. This test is based on the assumption that TSRs disrupt pairing over large contiguous chromosomal regions. That this might be true was suggested by the observation that TSRs follow the same rules for both the $C b x^{1} U b x^{1} /+$ and the $b x^{34 c} / U b x$ transvection effects (LEwIS 1954, 1985). One might expect then, that TSRs not having a breakpoint within the Ultrabithorax domain, would act uniformly throughout it. To determine whether TSRs behave as hypothesized, it was necessary to produce $R(U b x)$ chromosomes. Irradiated $U b x^{l} / T M 6 B$ males were crossed with $p b x^{2} / T M 1$ virgin females. Rearrangements were detected by an enlargement of the haltere in the $p b x^{2} / R\left(U b x^{I}\right)$ progeny. The putative $R(U b x)$ chromosomes were then tested over $b x^{34 e}$. A total of 62 such chromosomes was produced; in every case but one, the strength of a TSR was about the same in both systems (data not shown). The exceptional chromosome decreases synapsis dependent complementation of $p b x^{2}$, but not of $b x^{34 e}$. This is probably not a TSR effect since the associated lesion, $D f(3 R) 88 F ; 89 B$, does not visibly disrupt polytene chromosome pairing at the Ultrabithorax locus. In some other cases the observed phenotypes were extremely variable, but in all such cases, both the $p b x$ and the $b x$ phenotypes were affected. Since $p b x^{2}$ and $b x^{34 e}$ are $70 \mathrm{~kb}$ apart, it appears that TSRs with breakpoints outside of the Ultrabithorax domain act uniformly within it.

In order to determine the members of each transvection group, each mutation in a large collection of Ultrabithorax domain lesions was tested for the three transvection effects studied here. The TSR used in most transvection tests was $T(2 ; 3) 53 B, 81$ while the very similar rearrangement $T(2 ; 3) 57 B, 81 F$ was used in three cases. These two TSRs almost completely disrupt homologous pairing. The phenotypic, cytogenetic, and molecular characterizations of these crosses are presented in the tables. A summary of these crosses with commentary is presented below.

The extent of complementation of $b x^{34 e}$ with various 


\begin{tabular}{|c|c|c|c|c|c|c|c|c|}
\hline \multirow[b]{3}{*}{ Name } & \multirow[b]{3}{*}{ Location } & \multirow[b]{3}{*}{ Cytology } & \multicolumn{3}{|c|}{$p b x^{2}$} & \multicolumn{3}{|c|}{$C b x^{\prime} U b x^{\prime}$} \\
\hline & & & \multicolumn{2}{|c|}{ Phenotype } & \multirow[b]{2}{*}{ Results } & \multicolumn{2}{|c|}{ Phenotype } & \multirow[b]{2}{*}{ Results } \\
\hline & & & $p b x^{2}$ & $R\left(p b x^{2}\right)$ & & No $D p$ & $\overline{D p}$ & \\
\hline$b x d^{26 \sigma}$ & $+6.5(3)$ & $T(2 ; 3) 40 ; 89 E$ & 0 & 0 & $\mathrm{U}$ & 0 & . & $\mathrm{U}$ \\
\hline$b x d^{54 G}$ & $-0.5(9)$ & $T(2 ; 3) 59 C ; 89 E+\operatorname{In}(3 R) 88 C-D ; 92$ & 5 & 5 & $\mathbf{N}$ & 1 & 0 & $\mathbf{P}$ \\
\hline$b x d^{D B 3}$ & $-0.5(9)$ & $T(2 ; 3) 48 ; 89 E$ & 5 & 5 & $\mathbf{N}$ & 2 & 1 & $\mathbf{P}$ \\
\hline$b x d^{D B \sigma}$ & $-0.5(9)$ & $T(2 ; 3) 22 A ; 43 A-C ; 80 D ; 84 ; 89 E ; 92 F$ & 5 & 5 & $\mathrm{U}$ & . & . & . \\
\hline$b x d^{M X i}$ & $-2.0(6)$ & $I N(3 R) 89 E ; 90 E F$ & 5 & 5 & $\mathrm{~N}$ & 1 & 1 & $\mathbf{P}$ \\
\hline$b x d^{\prime \prime \prime}$ & $-2.5(2)$ & $T p(3 ; 1) 4 D ; 89 E ; 90 B 2$ & 5 & 5 & $\mathrm{~N}$ & 1 & 1 & $P$ \\
\hline$b x d^{657}$ & $-6.0(7)$ & $T(1 ; 3) X ; 81 ? ; 89 E$ & 5 & 5 & $\mathrm{U}$ & . & 0 & $\mathrm{U}$ \\
\hline$b x d^{106}\left[b x^{3}\right]$ & $-12.5(5)$ & $\ln (3 L R) 72 D 11-E 1 ; 89 E$ & 5 & 5 & $\mathrm{~N}$ & . & 1 & $\mathbf{p}$ \\
\hline$U a b^{\prime}$ & $-14.0(2)$ & Normal $[\operatorname{In}(3 R) 89 E, 89 E]$ & $3-5$ & $4-5$ & $\mathrm{~N} / \mathrm{P}$ & . & 2 & $\mathbf{P}$ \\
\hline$b x d^{C 5 A}$ & $-17.5(5)$ & $\ln (3 R) 89 B ; 89 E$ & $2-3$ & $* 4-5$ & $\mathbf{P}$ & . & 1 & $\mathbf{P}$ \\
\hline$b x d^{\prime \prime \theta}$ & $-17.5(5)$ & $T p(3 ; 3) 66 ; 89 B 5 ; 89 E$ & $1-4$ & 5 & $P$ & . & 0 & $\mathrm{~N}$ \\
\hline$b x d^{\prime \prime \prime}$ & $-23.0(7)$ & $T p(3 ; 3) 89 E ; 91 D ; 92 A$ & $2-5$ & $* 5$ & $P$ & . & 0 & $\mathrm{~N}$ \\
\hline$b x d^{\prime k 3}$ & $-23.0(7)$ & $\operatorname{In}(3 R) 89 C ; 89 E$ & $1-3$ & $* 3-5$ & $P$ & . & 1 & $\mathrm{P}$ \\
\hline$U b x^{5.12}$ & -30.0 & $\operatorname{In}(3 R) 89 E ; 90 A$ & $2-3$ & $4-5$ & $\mathbf{P}$ & . & 0 & $\mathrm{~N}$ \\
\hline$U b x^{8.8}$ & -37.0 & Normal $[\operatorname{In}(3 R) 89 E, 89 E]$ & $1-2$ & $4-5$ & $\mathrm{P}$ & . & 0 & $\mathrm{~N}$ \\
\hline$U b x^{5.22}$ & -45.0 & $T p(3 ; 4 ?) 89 A-89 E 1.2 ; ?$ & $2-4$ & 5 & $\mathrm{P}$ & . & 0 & $\mathrm{~N}$ \\
\hline$U b x^{6.26}$ & -47.0 & $\operatorname{In}(3 L R) 75 C ; 89 E+T(2 ; 3) 59 E ; 75 C$ & 5 & 5 & $\mathbf{U}$ & . & 0 & $\mathrm{U}$ \\
\hline$U b x^{882}$ & -75.0 & $\operatorname{In}(3 R) 87 ; 89 E 1.2$ & $3-5$ & 5 & $\mathrm{P}$ & . & 0 & $\mathrm{~N}$ \\
\hline$U b x^{4.30}$ & -85.0 & $T(2 ; 3) 34 ; 89 E 1.2$ & 5 & 5 & $\mathrm{U}$ & . & 0 & $\mathrm{U}$ \\
\hline$U b x^{5.2326}$ & -87.0 & Normal [?] & $2-4$ & $4-5$ & $\mathrm{P}$ & . & 0 & $\mathrm{~N}$ \\
\hline$U b x^{12.5}$ & -92.0 & $\operatorname{In}(3 R) 88 B ; 89 E 1.2$ & $2-4$ & $4-5$ & $P$ & . & 0 & $\mathbf{N}$ \\
\hline
\end{tabular}

Mutations in brackets are in cis with the preceding allele. Sizes/locations are in kilobases, the size of the affected restriction fragment in parenthesis. Cytology in brackets derives from genetic or molecular data. The TSR in $R\left(p b x^{2}\right)$ is $T(2 ; 3) 53 B, 81$ or, if marked with an "*," $T(2 ; 3) 57 B, 81 F . D p$ is $D p P 10$, an insertion of one wild-type copy of the Ultrabithorax domain into the left arm of the second chromosome. For an explanation of the numerical phenotype scores in the rightmost six columns, see MATERIALS AND METHODS. The results column indicates whether the genotype is transvection positive $(\mathrm{P})$, negative $(\mathrm{N})$, undefined $(\mathrm{U})$, or no information $(\cdot)$. Molecular data from KERRIDGE and Morata (1982), Bender et al. (1983, 1985), Karch et al. (1985), SANCHeZ-Herrero et al. (1985), LindSLeY and Zimm (1987), WeinzierL et al. (1987), RowE and Акам (1988). Cytology from these references or from personal observations.

alleles of $U b x$ in the absence of other chromosome rearrangements has been extensively documented elsewhere (KERRIDGE and MORATA 1982; Lewis 1954). This information and some of my own experiments are summarized here because combining the results allows the determination of the $b x^{34 e}$ transvection group. These phenotypes are not listed in the tables, although the molecular characterizations of the mutations are. Point and pseudopoint $U b x$ alleles $\left(U b x^{1}, U b x^{9.22}, U b x^{195}\right)$ are transvection positive with $b x^{34 e}$ (notum scores of $0-2$ ), but no breakpoint allele is (notum score of 5). It has been previously reported that $U b x^{5.2326}$ complements $b x^{34 e}$ to a level intermediate between pseudopoint and breakpoint mutations and is cytologically normal, yet is a breakpoint mutation (KeRRIDGe and Morata 1982; AKam et al. 1985). Unfortunately, on reexamination, the notum transformation score was 5 . Hence, it is impossible to determine if the originally reported phenotype was due to transvection with $b x^{34 e}$.

$C 1$ is a hybrid $a b d-A / U b x$ gene produced by a large deletion of parts of the $U b x$ and $a b d-A$ domains; it is functionally $b x^{+}$and $b x d^{-}$(CASANOVA, SANCHEZ-HeRRERo and MOrata 1988; Rowe and AKam 1988). The double mutant chromosome $U b x^{9.22} C 1$ is func- tionally $U b x^{-}$due to the $U b x$ mutation, yet a large region surrounding the site of the $b x^{34 e}$ lesion is intact. Flies of the genotype $U b x^{9.22} C 1 / b x^{34 e}$ (士TSR) have a notum score of 5 . The $a b x$ alleles are transvection positive with both $b x^{34 e}$ and $U b x^{1}$ (PEIFER and BENDER 1986). Therefore, the phenotypes of $b x^{34 e} / a b x$ genotypes are not examined here because the identity of the mutation which complements in the heterozygote can only be determined from genotypes such as $a b x U b x^{I} / b x^{34 e}$.

The phenotypes of flies carrying $p b x^{2}$ heterozygous with many different mutations, both in the presence and absence of a TSR, are shown in the tables. $p b x^{2}$ is transvection positive with $U b x$ point, pseudopoint, and most breakpoint alleles. The $T p(3 ; 3) b x d^{100}$ breakpoint marks the distal limit for transvection positive rearrangements. Pairing dependent complementation is mediated by the $b x d$ (distal) part of the transposition since $D f(3 R) b x d^{100}$ has the same phenotype (Tables 1 and 3). This clearly demonstrates that no $U b x$ transcription unit DNA is necessary in trans to $p b x^{2}$ for pairing dependent complementation to occur. The $b x d$ breakpoints distal to $b x d^{100}$ were not transvection positive with $p b x^{2}$. As expected, neither $b x d^{121}$ nor $C 1$, two deficiencies spanning $p b x^{2}$, was transvection posi- 
TABLE 2

Insertion and point mutations

\begin{tabular}{|c|c|c|c|c|c|c|c|c|}
\hline \multirow[b]{3}{*}{ Name } & \multirow[b]{3}{*}{ Location } & \multirow[b]{3}{*}{ Mutation } & \multicolumn{3}{|c|}{$p b x^{2}$} & \multicolumn{3}{|c|}{$C b x^{I} U b x^{I}$} \\
\hline & & & \multicolumn{2}{|c|}{ Phenotype } & \multirow[b]{2}{*}{ Results } & \multicolumn{2}{|c|}{ Phenotype } & \multirow[b]{2}{*}{ Results } \\
\hline & & & $p b x^{2}$ & $R\left(p b x^{2}\right)$ & & No $D p$ & $D p$ & \\
\hline$b x d^{K}$ & -2.5 & Gypsy insertion & $2-5$ & $2-5$ & $\mathrm{~N}$ & 2 & . & $\mathbf{P}$ \\
\hline$b x d^{5 l j}$ & -17.5 & Gypsy insertion & $0-2$ & $2-3$ & $\mathbf{P}$ & 1 & 1 & $\mathbf{P}$ \\
\hline$b x d^{I}$ & -21.0 & Gypsy insertion & 0 & $0-2$ & $\mathbf{P}$ & 2 & 1 & $\mathbf{P}$ \\
\hline$U b x^{\prime}$ & -32.0 & Doc insertion & $1-2$ & $4-5$ & $\mathbf{P}$ & . & 0 & $\mathrm{~N}$ \\
\hline$C b x^{1}$ & -44.0 & $17 \mathrm{~kb}\left[=p b x^{\prime}\right.$ DNA $]$ insert & . & · & $\cdot$ & . & . & $\cdot$ \\
\hline$U b x^{195}$ & -50.0 & Nonsense mutation & $1-2$ & $3-5$ & $\mathbf{P}$ & . & 0 & $\mathbf{N}$ \\
\hline$U b x^{M-4}$ & $?$ & Point mutation? & 0 & 1 & $\mathbf{P}$ & 1 & . & $\mathbf{P}$ \\
\hline$b x^{3}$ & -57.0 & Gypsy insertion & . & . & . & 2 & . & $\mathbf{P}$ \\
\hline$b x^{34 e}$ & -63.5 & Gypsy insertion & . & . & . & 2 & . & $\mathbf{P}$ \\
\hline
\end{tabular}

For details, see legend to Table 1.

tive with it. Of the pseudopoint mutations in the $b x d$ region, $p b x^{I}$ and $b x d^{K}$ were not transvection positive, while $b x d^{I}$ and $b x d^{5 / j}$ were. Transvection of $p b x^{2}$ with $b x d^{1}$ was more evident in the combination $b x^{3} b x d^{1}$, which has a stronger haltere transformation. The phenotypes of $b x d^{K}$ genotypes were extremely variable, even between one side of the fly and another (see below). $U a b^{l}$ also has a somewhat variable $p b x$ phenotype; if this mutant transvects with $p b x^{2}$, the effect is too slight to be reliably detected in this background. $b x d^{110}$ was transvection positive, but the penetrance of the complemented phenotype was low.

The $C b x^{l} U b x^{l} /+$ transvection effect differs from the two cases described above in that when the chromosomes are synapsed, the extra function is produced by the chromosome located in trans to the mutations (LEwIS 1955). Thus the transvection group for $C b x^{I}$ $U b x^{l}$ contains mutations which block the response to the double mutant. Crosses were made to a series of mutations similar to that described above for $p b x^{2}$, with results shown in the tables. The resulting gain of function phenotype, which is not present with any of the tested chromosomes until they are made heterozygous with $C b x^{I} U b x^{l}$, is assumed to result from transvection. However, this was only demonstrated directly for $+, b x^{3}, b x d^{5 l j}$ and $p b x^{2}$ (data not shown). One copy of $D p P 10$, an insertional duplication of the Ultrabithorax domain located in the second chromosome, was used to rescue lethal or poorly viable genotypes. The phenotypes recorded here are generally in agreement with those reported in BABU, SelvakuMAR, and BHOSEKAR (1987) and MiCOL and GARCIABELLIDO (1988).

Of the point and pseudopoint mutations, only lethal $U b x$ alleles eliminated the $C b x^{I} U b x^{I}$ transformation. A homozygous viable allele, $U b x^{M 4}$, greatly reduced the transformation. None of $a b x^{1}, a b x^{2}, b x^{34 c}$, or $b x^{3}$ strongly suppressed the $C b x^{I} U b x^{l}$ effect. Heterozygotes of $C b x^{I} U b x^{l}$ with $a b x^{I} b x^{2} p b x^{I}$ did not differ significantly in the wing transformation from heterozygotes with $a b x^{1}, b x^{3}$, or $p b x^{1}$. A synergistic interaction of $b x$ and $b x d$ was observed: $D p P 10 /+; C b x^{1} U b x^{1 /}$ Test had a much weaker wing transformation when Test was $b x^{3} b x d^{1}$ than it was when Test was $b x d^{I}, b x^{3}$, or $a b x^{1} b x^{3} p b x^{1}$.

All $U b x$ breakpoint alleles tested were not transvection positive with $C b x^{1} U b x^{1}$. This was also true for $C 1$, despite its residual $U b x^{+}$activity. The behavior of small lesions in the $b x d$ region was complicated; $b x d^{5 l j}$ definitely decreased the transformation while $b x d^{K}, p b x^{1}$, $b x d^{I}$, and $p b x^{2}$ did not. The $b x d$ breakpoint mutations generally suppressed the phenotype, but not completely. The copy of $U b x^{+}$in $D p P 10$ pairs rarely, if at all, with the third chromosome, since $C b x$ transformations were not observed in either $D p P 10 /+; C b x^{I}$ $U b x^{1} / D f P 10$ or $D p P 10 /+; C b x^{I} U b x^{I} / U b x^{X}$ genotypes. However, $D P P 10$ apparently can affect the phenotype of certain genotypes in a nonpairing dependent manner. For every $b x d$ allele which was tested both with and without the duplication, the latter had a significantly stronger wing transformation. This is less evident in the tables since the phenotypic classes used were quite broad. Additionally, both DPP115 (an insertion of the entire bithorax complex into the heterochromatin of the $X$ chromosome) and $D p P 10$ eliminated the weak wing transformation seen with the TM1 balancer chromosome.

The discovery that $b x d^{K}$ was transvection negative with $p b x^{2}$ prompted the series of crosses shown in Table 5. The variability of $b x d^{K}$ is a property of that allele independent of pairing. It produces patchy transformations and a similar distribution of mild to extreme phenotypes with $U b x^{1}, D f(3 R) U b x^{109}$, $T p b x d^{100}, p b x^{1}$, and $p b x^{2}$. Conceivably, $b x d^{K}$ completely blocks $p b x^{2}$ transvection, but this variable $c$ is regulatory defect masks the effect. Accordingly, the $b x d^{K}$ chromosome was X-rayed and two new $U b x$ alleles recovered. These mutations are functionally $U b x^{-}$and 
TABLE 3

Deletion mutations

\begin{tabular}{|c|c|c|c|c|c|c|c|c|}
\hline \multirow[b]{3}{*}{ Name } & \multirow[b]{3}{*}{ Proximal } & \multirow[b]{3}{*}{ Distal } & \multicolumn{3}{|c|}{$p b x^{2}$} & \multicolumn{3}{|c|}{$C b x^{\prime} U b x^{\prime}$} \\
\hline & & & \multicolumn{2}{|c|}{ Phenotype } & \multirow[b]{2}{*}{ Results } & \multicolumn{2}{|c|}{ Phenotype } & \multirow[b]{2}{*}{ Result: } \\
\hline & & & $p b x^{2}$ & $R\left(p b x^{2}\right)$ & & No $D p$ & $D p$ & \\
\hline$D f U b x^{I 0 y}$ & «-Ubx & $+89.5(7)$ & 5 & 5 & $\mathrm{U}$ & . & . & . \\
\hline DfP 10 & «-Ubx & $+35.5(1)$ & . & . & . & . & $0^{a}$ & $\mathrm{U}$ \\
\hline$b x d^{\prime \prime \prime}$ & $-2.5(2)$ & $U b x \rightarrow$ & 5 & 5 & $\mathrm{~N}$ & 1 & I & $\mathbf{P}$ \\
\hline$p b x^{l}$ & -3.0 & +14.0 & 5 & 5 & $\mathrm{~N}$ & 2 & . & $P$ \\
\hline$p b x^{2}$ & $-13.0(2)$ & $+1.0(4)$ & 5 & . & $\mathrm{N}$ & 2 & . & $P$ \\
\hline$b x d^{121}\left[b x^{34 e}\right]$ & -15.0 & $+62.5(2.5)$ & 5 & 5 & $\mathrm{U}$ & . & 0 & $\mathbf{U}$ \\
\hline$b x d^{I f(t)}$ & $\ll-U b x$ & $-17.5(5)$ & $1-4$ & 5 & $P$ & . & 0 & $N$ \\
\hline$C I$ & -51.0 & +48.0 & 5 & 5 & $\mathrm{U}$ & . & 0 & $\mathrm{U}$ \\
\hline$a b x^{\prime}$ & -79.0 & -73.0 & . & . & . & 2 & . & $P$ \\
\hline$a b x^{2}$ & -79.0 & -77.5 & . & . & . & 2 & . & $P$ \\
\hline$U b x^{9.22}$ & -104.5 & -103.0 & $1-2$ & $3-5$ & $\mathbf{P}$ & . & 0 & $\mathbf{N}$ \\
\hline
\end{tabular}

For details, see legend to Table 1 .

${ }^{a} \mathrm{TpP} 10 / \mathrm{Cbx} \mathrm{x}^{\prime} \mathrm{Ubx}$.

are similar to other $U b x$ breakpoint alleles when heterozygous with $b x^{34 e}$ and $U b x^{M 4}$ (data not shown). $U b x^{S 205-2}$ is associated with the rearrangement $I n$ (3R) $87 D, 89 E . U b x^{S 205-1}$ has one breakpoint at $89 \mathrm{E}$ and the other in heterochromatin, it segregates with the $Y$ and is presumably $T(Y ; 3) 89 E . U b x^{S 205-2}$ has the sort of rearrangement which typically has only weak TSR effects (see above and Table 1). The double mutant $U b x^{S 205-2} b x d^{K}$ still partially complements $p b x^{2}$. The transformation of the noncomplemented portions of the haltere frequently is patchy, suggesting that $b x d^{K}$ only blocks that fraction of the pairing dependent complementation which corresponds to its own variable loss of function phenotype. $b x d^{K}$ is a gypsy mutation and is suppressed in a $s u(H w)^{2}$ homozygous background (BENDER et al. 1983). In this background, $U b x^{S 205-2} b x d^{K} / p b x^{2}$ complement to a greater degree and the patchy transformation typical of $b x d^{K}$ is not observed. This suggests that it is the action of the gypsy, rather than the lesion associated with its insertion, which is responsible for the phenotype of $b x d^{K}$.

\section{DISGUSSION}

The transvection groups for $p b x^{2}$ and $C b x^{l} U b x^{1}$ can be read directly from Tables 1 through 4 . Mutations with an " $\mathrm{N}$ " in the results column are members of the respective transvection group, those with a "P" are not members, and those with a " $U$ " cannot be assigned. The transvection group for $p b x^{2}$ is composed of $b x d^{54 G}, b x d^{D B 3}, b x d^{M X 1}, b x d^{111}, b x d^{106}, b x d^{K}$, and $p b x^{l}$. The transvection group for $C b x^{1} U b x^{l}$ includes $b x d^{100}, b x d^{110}$, and as expected, all $U b x$ lethal alleles as well. For $b x d^{100}$ it is more likely that this classification results from the transposition of the $U b x$ transcription unit to another chromosome than from the position of the breakpoint within $b x d$. The inclusion of the $b x d^{110}$ lesion in this transvection group is also some- what problematical. Since the pairing dependent complementation of $b x d^{110}$ with $p b x^{2}$ is not very penetrant, it is possible that the corresponding feeble response to $C b x^{I} U b x^{I}$ was simply not detected.

The members of the transvection group for $b x^{34 e}$, from KERRIDGE and MORATA (1982) and Table 1, are $U b x^{5.12}, U b x^{8.8}, U b x^{5.22}, U b x^{882}, U b x^{5.2326}$, and $U b x^{12.5}$. The pseudopoint mutations $U b x^{1}, U b x^{9.22}$, and $U b x^{195}$ are not members. Surprisingly, the double mutant $U b x^{9.22} C 1$ is transvection undefined for $b x^{34 t}$. It is not possible from the current data to determine what role, if any, the $b x d$ region plays in this transvection effect. (Such an analysis requires $b x d^{\text {breakpoint }} U b x^{\text {pseudopoint }}$ chromosomes.) At least the $p b x^{1}$ DNA is not required since the double mutant $U b x^{l} p b x^{l}$ is transvection positive with $b x^{34 e}$ (D. MATHOG, unpublished observations).

Before discussing these transvection groups further, it is important to consider the synapsis disrupting effects of breakpoints within the Ultrabithorax domain. In particular, to what extent do TSR effects determine membership in a transvection group? In this paper 61 TSRs outside of the Ultrabithorax domain are shown to disrupt pairing throughout the gene. Only one mutation had differential effects on $b x^{34 e}$ and $p b x^{2}$ transvection, but it was not associated with a classical TSR (LEwIS 1954). Nevertheless, one would expect that TSR effects could be either symmetric or asymmetric around a single breakpoint within the Ultrabithorax domain. Apparently, small paracentric chromosomal inversions have symmetric TSR effects since $b x d^{C 5 A}$ and $b x d^{183}$, when paired with $p b x^{2}$ and $C b x^{1} U b x^{1}$, have approximately proportional phenotypes (data not shown). Other classes of chromosome rearrangements, such as translocations between the second and third chromosomes and pericentric inversions, may very well have asymmetric effects on pairing. If we assume that disruption of pairing distal to 
breakpoints is entirely responsible for membership in the $p b x^{2}$ transvection group, then DNA absolutely required to complement $p b x^{2}$ lies distal to the $b x d^{M X 1}$ breakpoint and one cannot determine whether or not sequences from there to the $b x d^{106}$ breakpoint are required as well. If, on the other hand, the $b x d^{106}$ chromosome can pair distal to its breakpoint, then DNA from around that breakpoint and distal to it is required for $p b x^{2}$ transvection. The distal and proximal ends of the $b x^{34 e}$ transvection group are defined by small inversions which demonstrably pair distal to their breakpoints and should pair proximally as well (based on their similarity to $b x d$ rearrangements which are transvection positive with $\left.C b x^{1} U b x^{1}\right)$. This constitutes a strong argument that TSR effects do not determine membership in this group.

Position effects near breakpoints, distinct from any longer range TSR effects, may also exist. Aside from the data at hand, there is no indication whether this local disruption of pairing extends for bases or megabases. No consistent estimate of the maximum range of this putative effect can be derived from the current data. For example, the distance separating the lesions in the transvection negative pair $U b x^{12.5}$ and $b x^{34 e}$ is about $30 \mathrm{~kb}$, whereas the distance for the transvection positive pair $b x d^{C 5 A}$ and $p b x^{2}$ is between 4 and $17 \mathrm{~kb}$. There is no evidence of phenotypic gradients as breakpoints approach $b x^{34 e}$ and $p b x^{2}$. Instead, one finds a contiguous block of transvection negative mutations and phenotypes outside of this block correlate very well with the expected TSR properties of the rearrangements (Table 1). If the layout of the transvection groups results from a local pairing disrupting effect, such an effect must act in predefined chromosomal regions, perhaps corresponding to DNA loops or other structures. Such an explanation has its own difficulties: what sort of chromosomal structure would correspond to all of one transcription unit, but only part of another? In any case, simple proximity to a breakpoint does not define membership in a transvection group. For example, $U b x^{5.12}$ is closer to $p b x^{2}$ than it is to $b x^{34 e}$, yet it is transvection positive with the former.

Each of the three transvection effects may be modeled using the functions send, receive and respond. Ultimately, the respond function for all three effects is the synthesis of $U b x$ protein(s). Conversely, receive may be different for all three of the transvection effects. $p b x^{2}$ and $b x^{34 e}$ are defective in their respective send functions, but are complemented when a working send is paired with them. $C b x^{l}$ has a neomorphic send which acts strongly in cis and weakly in trans on receive. The resulting $C b x$ transformation can be blocked either in cis or in trans by an Ubx mutation (respond).

The DNA corresponding to the $p b x^{2}$ send unit is either similar in size to the $p b x^{2}$ deficiency or it is located within the distal few kilobases of that deficiency (see above). Either interpretation includes the $5^{\prime}$ end of the $b x d$ early transcription unit (HoGNESS $e t$ al. 1985, LiPSHITZ, PEATTIE and Hogness 1987). One argument favoring the more extensive send unit is that chromosomes which are transvection positive with $p b x^{2}$, and thus have a functioning send unit, all contain a piece of wild type DNA extending both proximally and distally beyond the $p b x^{2}$ deficiency.

The DNA corresponding to the $b x^{34 e}$ send unit is more extensive. Mutations which do not send to $b x^{34 e}$ map throughout the $U b x$ transcription unit. However, no suitable breakpoint mutations fall within the final $10 \mathrm{~kb}$ of the gene, so it has not been possible to determine if this region is also required.

$C b x^{L}$ receive is difficult to map within the $U b x$ transcription unit since respond requires the production of $U b x$ protein. Nevertheless, it is possible to exclude the $a b x, b x$ and $p b x$ regulatory regions as mediating receive either singly or in combination (Tables 2 and 3). $C b x^{I} U b x^{I}$ transvection is often partially suppressed by $b x d$ mutations, but the location of the breakpoint or insertion and the magnitude of the resulting suppression are poorly correlated (Tables 1 and 2). Therefore, either $b x d^{+}$is not receive, or it is not the only receive, for $C b x^{1}$ send.

The two deficiencies $C 1$ and $b x d^{121}$, which are roughly similar in size and position, have unexpected phenotypes. $C b x^{1} U b x^{1}$ is transvection positive with both $p b x$ alleles (which more or less cover the $b x d$ DNA deleted in $b x d^{I 2 J}$ ), with $U a b^{I}$ (which has a breakpoint and phenotype close to that of $b x d^{127}$ ), and with $b x d^{106}$ (which is also a $b x b x d$ double mutant). Therefore, one must posit some new effect to explain why $b x d^{121}$ is transvection undefined with $C b x^{i} U b x^{1}$. Presumably such an effect could also occur with $C 1$, which is a deletion of comparable scale and location (Table 3). This new effect might also explain why $C b x^{l} U b x^{l} /$ $C 1$ and $b x^{34 e} / U b x^{9.22} C 1$ are not transvection positive. One explanation might have been that deficiencies of this size have anomalously large effects on pairing. This is apparently not the case for $b x d^{121}$ since it is transvection positive with the distally located lesion $i a b-4,5^{D B}$ (KARCH et al. 1985; E. B. LEWIs, personal communication). Whether $C l$ also exerts a polar effect on transvection is not yet known.

Two effects are noted with respect to $C b x^{I} U b x^{I}$ transvection. The first is a synergistic interaction between $b x^{3}$ and $b x d^{1}$ such that the double mutant responds to $C b x^{I} U b x^{I}$ more weakly than does either mutation alone. BABU, SelvakUMAR and BHOSEKAR (1987) also observed this synergism in their studies of the interactions between multiple gypsy mutations in the same gene. In the second effect, which has not previously been reported, $D P P 10$ reduces the wing to haltere transformation of $C b x^{l} U b x^{1} / b x d$ genotypes, 


\begin{tabular}{|c|c|c|c|c|c|c|}
\hline \multirow[b]{3}{*}{ Name } & \multicolumn{3}{|c|}{$p b x^{2}$} & \multicolumn{3}{|c|}{$C b x^{\prime} U b x^{\prime}$} \\
\hline & \multicolumn{2}{|c|}{ Phenotype } & \multirow[b]{2}{*}{ Results } & \multicolumn{2}{|c|}{ Phenotype } & \multirow[b]{2}{*}{ Results } \\
\hline & $\overline{p b x^{2}}$ & $R\left(p b x^{2}\right)$ & & No $D p$ & $\overline{D p}$ & \\
\hline$a b x^{\prime} b x^{3} p b x^{\prime}$ & $\cdot$ & . & . & 2 & 2 & $\mathbf{P}$ \\
\hline$b x^{3} b x d^{1}$ & $0-2$ & $3-4$ & $\mathrm{P}$ & . & 1 & $P$ \\
\hline$U b x^{\prime} p b x^{\prime}$ & 5 & 5 & $\mathrm{~N}$ & . & . & . \\
\hline$C b x^{I} U b x^{I}$ & . & - & . & . & 0 & $\mathrm{~N}$ \\
\hline$b x^{3}\left(b x^{1} l b x^{1} b x d^{1} p b x^{1}\right.$ & 5 & 5 & $\mathrm{U}$ & . & . & . \\
\hline+ & . & . & . & 2 & 2 & $\mathrm{P}$ \\
\hline$T M I[\operatorname{In}(3 L) 63 C ; 72 E+\operatorname{In}(3 L R) 69 E ; 91 C+\operatorname{In}(3 R) 89 B ; 97 D]$ & 0 & 0 & $\mathbf{U}$ & 1 & 0 & $P$ \\
\hline
\end{tabular}

For details, see legend to Table 1 .

TABLE 5

Phenotypes of $b x d^{K}$

\begin{tabular}{|c|c|c|c|}
\hline Genotype $(a / b)$ & $a / b$ & $a / R(b)$ & $\frac{S u(H w)^{2} / a}{s u(H w)^{2} / b}$ \\
\hline$b x d^{K} / p b x^{2}$ & $2-5$ & $2-5$ & 0 \\
\hline$b x d^{K} / p b x^{I}$ & $2-5$ & $\cdot$ & . \\
\hline$b x d^{K} / T p b x d^{100}$ & $2-5$ & . & . \\
\hline$b x d^{K} / U b x^{\prime}$ & $2-5$ & $2-5$ & . \\
\hline$b x d^{K} / D f(3 R) U b x^{2 H \varphi}$ & $2-5$ & $\cdot$ & 0 \\
\hline$b x d^{K} \operatorname{In}(3 R) U b x^{5210-2} / p b x^{2}$ & $3-5$ & . & $2-3$ \\
\hline$b x d^{K} T(3 ; Y) U b x^{S 2115-1} / p b x^{2}$ & 5 & . & 5 \\
\hline
\end{tabular}

For details, see legend to Table 1 .

for all alleles of $b x d$ tested. The suppression is not evident in either $C b x^{l} U b x^{l} /+$ or $C b x^{l} U b x^{+} /+$(LEwIS 1955; CaSanova, SANCHEz-HerRero and Morata 1985), which perhaps explains why it has not been previously detected. The suppression is apparently not due to a maternally acting modifier since it is evident in reciprocal crosses of $b x d^{5 l j}$ with $D p P 10 /+; C b x^{I}$ $U b x^{I} /+$. Neither can it be due to a second chromosome dominant modifier linked to $D P P 10$ since another $U b x^{+}$duplication. $D p(3 ; 1) P 115$, has the same effect. Lastly, it does not appear that pairing of $D p P 10$ with the Ultrabithorax domain is involved: $T p P 10 / C b x^{l} U b x^{l}$ flies have normal wings and no synapsis of the transposed region was seen in a small number of polytene squashes (D. MATHOG, unpublished results). These results suggest either that the duplication competes for a required factor or that the duplication responds to the misexpression of $U b x$ proteins in the wing by producing some other product (also $U b x$ ?) which partially suppresses that misexpression.

The abstract concepts of send, receive and respond are useful for discussing transvection effects. However, the final goal is to discover the molecular mechanisms underlying these abstract terms. A simple class of transvection models has been suggested by ZACHAR, Chapman and Bingham (1985), Biggin et al. (1988), and by others. In this class of models, regulatory regions move passively to the promoter upon which they act. Left unanswered is how, given the distances involved and the ability to act on the homologous promoter on a paired chromosome, a regulatory region acts specifically on its target rather than on an equidistant, but incorrect, promoter. The $a b x / b x$ region, for example, would have to move at least 30 to $40 \mathrm{~kb}$ (BENDER et al. 1983). How does it avoid the neighboring promoters in lethal left of bithorax, $b x d$, and $a b d-A$ (SANCHEZ-HERRERo et al. 1985)? Furthermore, this simple mechanism does not predict the observed asymmetry in $p b x^{2}$ and $b x^{34 e}$ transvection: the former is complemented by a relatively small region of DNA which does not extend to the $U b x$ promoter whereas the latter requires an enormous unbroken piece of DNA which probably does include that promoter.

A model for the regulation of the Ultrabithorax domain can be derived by combining some elements of the above regulator-promoter models with ideas first presented in JACK and JUDD (1979) and LewIS (1954). This model explains many of the unexpected observations reported here and suggests a physical nature for send and receive. The normal cis-regulation of $U b x$ by $b x d^{+}$is not included in this model (but see below). Furthermore, this model only covers the initiation of regulatory interactions-it is assumed that a system exists to maintain the state of the gene.

The proposed model assumes that regulatory regions such as those in $C b x, p b x^{+}$, and $b x^{+}$act by physical contact on or near the regulated promoter. Two separate actions are required to bring about this juxtaposition (Figure 2). When these regions find themselves in the immediate vicinity of their target promoter, "passive transport" physically brings the two into working contact. The thermal motions of the DNA combined with some sticking mechanism (protein-protein, for instance) probably suffice. However, such regions are located in cis at distances of several tens of kilobases, and therefore require prior use of "active transport" to move close enough together so that passive transport will work. This is accomplished 
A
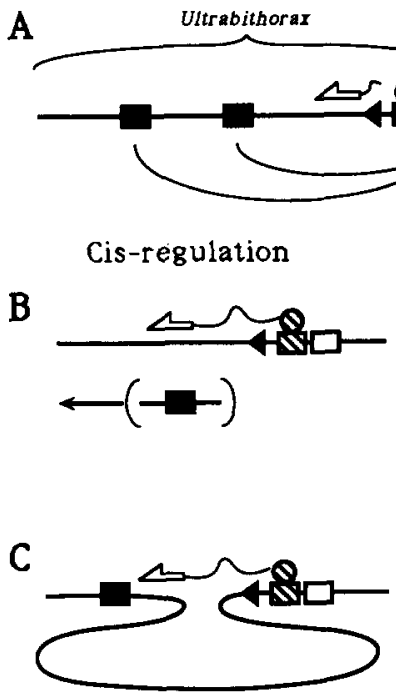

D

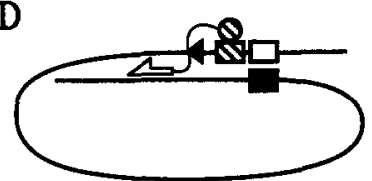

bithoraroid
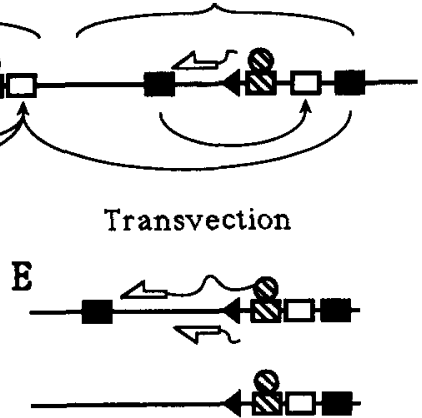

F

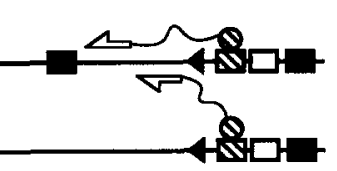

G
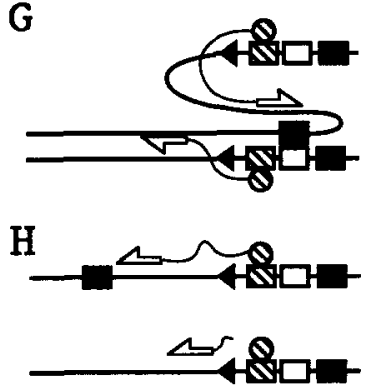

Figure 2.-A) A schematic illustration of the components of the Ultrabithorax domain which are involved in regulation. Solid boxes are regulatory send units, empty boxes are regulatory receive units, hatched boxes are "attach" sites for the 5 ' ends of localizing RNAs, hatched circles are "attach" mediating proteins, the open half-arrow is an RNA polymerase (shown shortly after the initiation of transcription), the thin wavy line is RNA, the thick line is DNA, and the solid arrowheads are transcription initiation sites. Regulatory interactions are indicated by the arrows. B) A localizing transcript is shown shortly after initiation. The regulatory region to be transported is far away. $\mathrm{B} \rightarrow \mathrm{C}$ ) Active transport: the localizing transcript is attached at both ends while RNA processing and packaging makes the distance between these ends much shorter than the equivalent path along the DNA. Consequently, send is brought near to receive. $\mathrm{C} \rightarrow \mathrm{D})$ Passive transport: once within range, send diffuses to, and interacts with, receive. The position of the RNA polymerase with respect to send in the illustration is arbitrary. $\mathrm{E} \rightarrow \mathrm{H}$ ) Transvection between $D f b x d^{\prime(t)}$ (upper chromosome) and $p b x^{2}$. The latter chromosome lacks DNA which includes the proximal send unit and regions up to, and possibly including, the normal $b x d$ promoter. The promoter on the $p b x^{2}$ chromosome is either the mutant remnant of the $b x d$ promoter or a cryptic promoter which is activated in its absence. This promoter is not transcribed in $p b x^{2}$ homozygotes. E) A localizing transcript on the $D f b x d^{\prime \prime \prime \prime}$ chromosome is shown as is a second transcript which cannot "attach" to the same chromosome because the "attach" site is filled. F) The $5^{\prime}$ end of a transcript from the $D f b x d^{\prime(x)}$ chromosome is captured by the $p b x^{2}$ chromosome. G) After active and passive transport, $p b x^{2}$ receive is activated by $D f b x d^{100}$ send. $\left.\mathrm{H}\right)$ The $p b x^{2}$ chromosome begins producing its own transcripts. One of these becomes a localizing transcript which transports distal $p b x$ send to $U b x$ receive.

by a "localizing" RNA transcript. Such transcripts are initially produced at some low rate which may be altered by subsequent regulatory interactions. The "localizing" transcripts either begin or end in the

vicinity of the target promoter. Initially, the $5^{\prime}$ end of the "localizing" transcript "attaches" to the chromosome in the vicinity of its own promoter (which does not need to be the promoter to be regulated). The RNA polymerase "attaches" the 3 ' end of this "localizing" transcript. Transcription proceeds and the nascent RNA is shortened by various processes. For example, it may be packaged into RNPs (SKUGLAND et al. 1983), spliced (OSHEIM, MILLER and BEYER 1985), or even degraded by an exoribonuclease (see below). In this manner regulatory regions which lie in or near the localizing transcript are dragged towards the target promoter.

Transvection in this model results from an error in active transport. First, the $5^{\prime}$ end of the localizing transcript cross attaches to the homologous chromosome. Following this misdirected active transport, interchromosomal passive transport occurs, leading to the observed transvection effects. Since the number of attachment sites for $5^{\prime}$ ends is expected to be limited, a few localizing transcripts present on one chromosome may block the action of similar transcripts originating on the homologous allele.

The cis regulatory actions of $C b x^{I}, p b x^{+}$, and $b x^{+}$can all be described by the proposed model. For $C b x^{l}$ and $b x^{+}$the localizing transcripts are either nonpolyadenylated transient transcripts or the nascent form of one of the known $U b x$ mRNA transcripts (HogNess $e t a l$. 1985; O'CoNNOR et al. 1988; KORNFELD et al. 1989). It is probable that one of the regulatory regions involved in $C b x^{I}$ action is within the $C b x^{l}$ insert and that $b x^{+}$lies in the vicinity of the $a b x$ lesions. The $b x^{34 e}$ transvection group has members proximal to $a b x$ and mutations with phenotypes similar to $C b x^{l}$ map in the extreme proximal ( $3^{\prime}$ ) end of the gene (BENDER et al. 1983). Therefore, a region in the proximal end of $U b x$ may also be required in both cases.

The application of the model to $p b x^{+}$regulation is somewhat different because there is strong evidence that $p b x^{+}$does not directly activate the $U b x$ promoter. This statement is based on the following observations: $p b x^{+}$send maps within the DNA deleted in $p b x^{2}$; pairing in the vicinity of the $U b x$ promoter occurs in heterozygotes of $U b x^{I}$ with $p b x^{2}, p b x^{I}$, and many $b x d$ pseudopoint and breakpoint mutations (from the $C b x^{1}$ $U b x^{1}$ data); yet only $p b x^{2}$ is transvection positive with $U b x^{I}$. The simplest explanation for these observations is that $p b x^{+}$send lies within and $p b x^{+}$receive lies just distal to the $p b x^{2}$ deletion, and that subsequent activation of the $U b x$ promoter is mediated entirely in cis from $p b x^{+}$receive. These observations are inconsistent with $p b x$ send acting directly upon the $U b x$ promoter. Diffusible RNA models (JACK and JUDD 1969; Micol and GARCIA-BELLIDO 1988) also fit the observations if only a small piece of the early $b x d$ transcript is required and it acts near the early $b x d$ promoter. However, the 
subsequent cis activation of the $U b x$ promoter would then require a distinct mechanism. In the model proposed here the obligate cis interaction is not an ad hoc assumption but it must hold true for any upstream regulatory region whose active transport is mediated by localizing transcripts which run toward the target promoter.

The passive transport mechanism is widely accepted and will not be discussed further here. With respect to "active transport," there are two previously described biochemical activities which could serve to "attach" the 5' end of a localizing RNA. The first is a processive $5^{\prime} \rightarrow 3^{\prime}$ exoribonuclease (LASATER and EICHLER 1984). If this protein binds directly or indirectly near the promoter of the localizing transcript, it could then capture the $5^{\prime}$ end of an RNA transcript before it is capped or bound by other proteins. The subsequent processive exonuclease activity, if sufficiently rapid, would greatly enhance the transport of regulator to promoter. Another possible "attach" mechanism is the formation of a hybrid between the $5^{\prime}$ end of the RNA and the template or, more likely, a nearby region of DNA. In this second mechanism, requirements for sequence complementarity would preclude erroneous interactions with nonhomologous genes, but allow transvection. There is some precedent for this mechanism: RNA/DNA hybrids are required for Tetrahymena telomerase action (GREIDER and BLACKBURN 1989) and for initiation of replication at the origin of replication of certain plasmids in $E$. coli (IтOH and TOMIZAwa 1980).

The requirement for a process beyond passive transport follows from a number of results. For example, the transvection negative results of $b x^{34 e}$ with $U b x^{12.5}$ and $U b x^{5.2326}$ are not predicted by passive transport only models (because there is no obvious reason why the wild type regulatory regions on these chromosomes cannot reach the promoter on the trans chromosome). Furthermore, even if the $U b x$ promoter on the $b x^{34 e}$ chromosome is unpaired when heterozygous with $U b x^{9.22} C 1$, it is not obvious why the $b x^{+}$region on the double mutant cannot interact with it. How has the diffusion distance changed? It is possible to rationalize these sorts of interactions with previously undetected chromosome pairing interactions. However, the model presented here is simpler. Indeed, it is essentially the model originally proposed by LEwIS (1954), except in the current version only the transcript, not the transcript and the polymerase, changes chromosomes.

The proposed model provides a rationale for several genetic results. $U b x^{I}$ does not transvect with $b x d$ mutations or $p b x^{I}$ for the $p b x$ phenotype because cross attachment of the localizing transcript from the $U b x^{l}$ chromosome either cannot occur ( $p b x^{l}$, some $b x d$ alleles) and/or regulation of the $U b x$ promoter is still blocked in cis even when $p b x^{+}$receive is activated ( $b x d$ mutations). The lack of transvection of $U b x^{9.22} C 1$ with $b x^{34 e}$ and of $C b x^{1} U b x^{1}$ with $C 1$ is caused by the absence of cross attachment at the $5^{\prime}$ end of the respective localizing transcripts. Yet $C 1$ can still be $b x^{+}$because a new localizing transcript from the $a b d-A$ promoter is available (Rowe and AKAM 1988).

Phenotypic gradients in the $b x$ and $b x d$ regions are associated with different gypsy insertions (BENDER $e t$ al. 1983; PEIFER and BENDER 1986). The direction of each gradient is aligned with its localizing transcript. In the present model the phenotypes could arise either from competition of some gypsy sequence with normal regulatory regions subsequent to active transport or from disruption of active transport by "detaching" the localizing transcript. The same mechanism can also explain how $b x d^{K}$ blocks $p b x^{+}$function either in $c i s$ or in trans. As a specific example, the "detach" mechanism can explain why $b x d^{1}$ has a $p b x$ mutant phenotype whereas a phenotypic revertant (which leaves one gypsy LTR) does not, even though both have early $b x d$ RNAs of identical (but mutant) sizes (HogNess $e t$ al. 1985). Explicitly, $b x d^{l}$ is inserted very near the end of several of the early $b x d$ transcripts (BENDER et al. 1983; LiPshitz, Peattie and Hogness 1987). If one of these transcripts is acting as a localizing transcript, then termination in the first gypsy LTR would "detach" that transcript at least $7.3 \mathrm{~kb}$ short of its target, whereas active transport in the phenotypic revertant would terminate in essentially the normal location (Modolell, Bender and Meselson 1983).

There is little experimental evidence contradictory to the proposed model. To my knowledge, the transient DNA loops which are predicted by both the proposed and enhancer only models have not yet been observed in the electron microscope. A report that $b x d$ transcripts are absent in parasegment 6 (AKAM $e t$ al. 1985) led to conclusions that these transcripts play no role in $p b x^{+}$function (Hogness et al. 1985; LIPShitz, Peattie and Hogness 1987). However, more recent observations have detected a small amount of $b x d$ RNA in embryos in parasegment 6 (IRISH, MARTINEZ-ARIAS and AKAM 1989). The model only concerns the initiation of regulated states, so the lack of $b x d$ transcripts later in development does not argue against it. This initiation of a regulated state for the $b x d$ region early in development would seem to require the appearance of clones of transformed cells resulting from early transvection of $p b x^{2}$ - which is not evident in the observed phenotypes. Patches of transformation resulting from many $U b x$ regulatory mutations are nonclonal, suggesting that intercellular signals modulate $U b x$ expression late in development (reviewed in Botas, Cabrera and Garcia-Bellido 1988). Since $p b x^{2}$ need not be mutant for this cell-cell regulatory function, subsequent regulation by this 
mechanism could smear the borders of such clones and result in the observed phenotypes.

Lastly, it is worth commenting on the generality of active transport. It seems likely that an RNA polymerase may not be able to pass through the site where the $5^{\prime}$ end of a localizing transcript is fixed to the chromosome. If so, such sites would normally lie outside the transcription unit which produces a gene's product. This appears to be the case for both the $U b x$ (coding) and $b x d$ (noncoding) units. This is the expected result if the Ultrabithorax domain evolved from a two promoter gene like Antennapedia (LAUGHON $e t$ al. 1986; O'CoNNOR et al. 1988). Other genes may have upstream regulatory units transcribed in the opposite direction from their structural units. Localizing transcripts which have never been coding may be "attached" downstream from their promoter. This would be efficient since the single localizing transcript extant at any given time could repeatedly scan for distant regulatory elements. It would also make the detection of such transcripts exceedingly difficult. Indeed, if "attach" is mediated by an exoribonuclease, such transcripts might only exist transiently as short oligoribonucleotides. Until recently such entities would have been totally undetectable, but with the advent of the polymerase chain reaction (SAIKI $e t$ al. 1985 ) it may now be possible to test this hypothesis.

I would like to thank G. Morata (Centro de Biología Molecular, Universidad Autónoma, Madrid) and H. LIPSHITz (Caltech, Pasadena) for providing space, proof reading, and encouragement, $E$. B. Lewis and A. Garcia-Bellido for providing stocks, and the referees for several helpful suggestions. This work was carried out in the laboratories of G. MoratA and H. Lipshitz. Funding was provided by Helen Hay Whitney Foundation and Muscular Dystrophy Association postdoctoral fellowships to D.M. and by a Developmental Biology grant from the Lucille P. Markey Charitable Trust to HowaRd D. LiPshitz.

\section{LITERATURE CITED}

Akam, M. E., A. Martinez-ARias, R. WeinzierL and C. D. Wilde, 1985 Function and expression of Ultrabithorax in the Drosophila embryo. Cold Spring Harbor Symp. Quant. Biol. 50: 195-200.

Babu, P., K. S. Selvakumar and S. Bhosekar, 1987 Studies on transvection at the bithorax complex in Drosophila melanogaster. Mol. Gen. Genet. 210: 557-563.

BeaChy, P. A., S. L. Helfand and D. S. Hogness, 1985 Segmental distribution of bithorax complex proteins during Drosophila development. Nature 313: 545-551.

Bender, W., M. Akam, F. Karch, P. A. Beachy, M. Peifer, P. SPIERER, E. B. Lewis and D. S. Hogness, 1983 Molecular genetics of the bithorax complex in Drosophila melanogaster. Science 221: 23-29.

Bender, W., B. Weiffendach, F. Karch and M. Peifer, 1985 Domains of cis-interaction in the bithorax complex. Cold Spring Harbor Symp. Quant. Biol. 50: 173-180.

Biggin, M. D., S. Bickel, M. Benson, V. Pirrotta and R. TJian, 1988 Zeste encodes a sequence-specific transcription factor that activates the Ultrabithorax promoter in vitro. Cell 53: 713722 .

Botas, J., C. V. Cabrera and A. Garcia-Bellido, 1988 The reinforcement-extinction process of selector gene activity: a positive feed-back loop and cell-cell interactions in Ultrabithorax patterning. Wilhelm Roux's Arch. Dev. Biol. 197: 424-434.

Casanova, J., E. Sanchez-Herrero and G. Morata, 1985 Contrabithorax and the control of spatial expression of the bithorax complex genes of Drosophila. J. Embryol. Exp. Morphol. 90: 179-196.

Casanova, J., E. Sanchez-Herrero and G. Morata, 1988 Developmental analysis of a hybrid gene composed of parts of the $U b x$ and $a b d-A$ genes of Drosophila. EMBO J. 7: 10971106 .

Gelbart, W., and C.-T. Wu, 1982 Interactions of zeste mutations with loci exhibiting transvection effects in Drosophila melanogaster. Genetics 102: 179-189.

Greider, C. W., and E. H. BLACKBuRn, 1989 A telomeric sequence in the RNA of Tetrahymena telomerase required for telomere repeat synthesis. Nature 337: 331-337.

Hogness, D. S., H. D. LipShitz, P. A. Beachy, D. A. Peattie, R. B. Saint, M. Goldschmidt-Clermont, P. J. Harte, E. R. Gavis and S. L. Helfand, 1985 Regulation and products of the $U b x$ domain of the bithorax complex. Cold Spring Harbor Symp. Quant. Biol. 50: 181-194.

IRISH, V. F., A. MARTINEZ-ARIAS and M. АKaM, 1989 Spatial regulation of the Antennapedia and Ultrabithorax homeotic genes during Drosophila early development. EMBO J. 8: 1527 1537.

ITOH, T., and J.-I. TomizawA, 1980 Formation of an RNA primer for initiation of replication of Col E1 DNA by ribonuclease H. Proc. Natl. Acad. Sci. USA 77: 2450-2454.

JACK, J. W., and B. H. JUDD, 1979 Allelic pairing and gene regulation: a model for zeste-white interaction in Drosophila melanogaster. Proc. Natl. Acad. Sci. USA 76: 1368-1372.

Karch, F., B. Weiffenbach, M. Peifer, W. Bender, I. Duncan, S. Celnicker, M. Crosby and E. B. Lewis, 1985 The abdominal region of the bithorax complex. Cell 43: 81-96.

Kerridge, S., and G. Morata, 1982 Developmental effects of some newly induced Ultrabithorax alleles of Drosophila. J. Embryol. Exp. Morphol. 68: 211-234.

Kornfeld, K., R. B. Saint, P. A. Beachy, P. J. Harte, D. A. PeATtIE and D. S. Hogness, 1989 Structure and expression of a family of Ultrabithorax mRNAs generated by alternative splicing and polyadenylation in Drosophila. Genes Dev. 3: 243258.

Laughon, A., A. M. Boulet, J. R. Bermingham and M. P. SCott, 1986 Structure of transcripts from the homeotic antennapedia gene of Drosophila melanogaster: Two promoters control the major protein-coding region. Mol. Cell. Biol. 6: 46764689.

LASATER, L. S., and D. C. EICHLER, 1984 Isolation and properties of a single-strand $5^{\prime} \rightarrow 3^{\prime}$ exoribonuclease from Ehrlich ascites tumor cell nucleoli. Biochemistry 23: 4367-4373.

LEFEVRE, G, 1976 A photographic representation and interpretation of the polytene chromosomes of Drosophila melanogaster salivary glands, pp. 31-66 in The Genetics and Biology of Drosophila, Vol. 1 A, edited by E. NoviTSKI and M. ASHBURNER. Academic Press, London.

LEwIS, E. B., 1954 The theory and application of a new method of detecting chromosomal rearrangements in Drosophila melanogaster. Am. Nat. 88: 225-239.

LEwIS, E. B., 1955 Some aspects of position pseudoallelism. Am. Nat. 89: 73-89.

LEwIS, E. B., 1963 Genes and developmental pathways. Am. Zool. 3: 33-56.

LEWIS, E. B., 1978 A gene complex controlling segmentation in Drosophila. Nature 276: 565-570.

LEWIS, E. B., 1981 Developmental genetics of the bithorax complex in Drosophila. ICN-UCLA Symp. Mol. Cell. Biol. 23: 189_ 208. 
LEwIS, E. B., 1982 Control of body segment differentiation in Drosophila by the bithorax gene complex, pp. 269-289 in Embryonic Development: Genes and Cells. Proceedings of the IX Congress of The International Society of Developmental Biology, edited by M. Burger. Alan R. Liss, New York.

LEwIs, E. B., 1985 Regulation of the genes of the bithorax complex in Drosophila. Cold Spring Harbor Symp. Quant. Biol. 50: $155-164$.

Lindsley, D. L., and E. H. GRell, 1968 Genetic variations of Drosophila melanogaster. Carnegie Inst. Wash. Publ. 627.

LindsLEy, D. L., and G. ZIMm, 1987 The genome of Drosophila melanogaster, Part 3: Rearrangements. Drosophila Inform. Serv. 65.

Lipshitz, H. D., D. A. Peattie and D. S. Hogness, 1987 Novel transcripts from the Ultrabithorax domain of the bithorax complex. Genes Dev. 1: 307-322.

Martinez-Arias, A., and P. A. Lawrence, 1985 Parasegments and compartments in the Drosophila embryo. Nature 313: 639.

Metz, C. W., 1916 Chromosome studies on the Diptera. II. The paired association of chromosomes in the Diptera, and its significance. J. Exp. Zool. 21: 213-279.

Micol, J. L., and A. Garcia-Bellido, 1988 Genetic analysis of "transvection" effects involving Contrabithorax mutations in Drosophila melanogaster. Proc. Natl. Acad. Sci. USA 85: $1146-$ 1150.

Modolell, J., W. Bender and M. Meselson, 1983 Drosophila melanogaster mutations suppressible by the suppressor of Hairywing are insertions of a 7.3-kilobase mobile element. Proc. Natl. Acad. Sci. USA 80: 1678-1682.

O'Connor, M. B., R. Binari, L. A. Perkins and W. Bender, 1988 Alternative RNA products from the Ultrabithorax domain of the bithorax complex. EMBO J. 7: 435-445.
Osheim, Y. N., O. L. Miller, JR., and A. L. Beyer, 1985 RNP particles at splice junction sequences on Drosophila chorion transcripts. Cell 43: 143-151.

Peifer, M., and W. Bender, 1986 The anterobithorax and bithorax mutations of the bithorax complex. EMBO J. 5: 2293-2303.

Peifer, M., F. Karch and W. Bender, 1988 The bithorax complex: control of segmental identity. Genes Dev. 1: 891-898.

RowE, A., and M. АкаM, 1988 The structure and expression of a hybrid homeotic gene. EMBO J. 7: 1107-1114.

Saiki, R. K., S. Scharf, F. Faloona, K. B. Mullis, G. T. Horn, H. A. ERLich and N. ArnheIm, 1988 Primer-directed enzymatic amplification of DNA with a thermostable DNA polymerase. Science 230: 487-491.

Sanchez-Herrero, E., I. Vernos, R. Marco and G. Morata, 1985 Genetic organization of Drosophila bithorax complex. Nature 313: 108-113.

Skugland, U., K. Andersson, B. Bjorkorth, M. Lamb and B. DANEHOLT, 1983 Visualization of the formation and transport of a specific hnRNP particle. Cell 34: 847-855.

Weinzierl, R., J. M. Axton, A. Ghysen and M. AKam, 1987 Ultrabithorax mutations in constant and variable regions of the protein coding sequence. Genes Dev. 1: 386-397.

White, R. A. H., and M. E. AKAM, 1985 Contrabithorax mutations cause inappropriate expression of Ultrabithorax products in Drosophila. Nature 318: $567-569$.

White, R. A. H., and M. WrLcox, 1985 Regulation of the distribution of Ultrabithorax proteins in Drosophila. Nature 318: 563-567.

Zachar, Z., C. H. Chapman and P. M. Bingham, 1985 On the molecular basis of transvection effects and the regulation of transcription. Cold Spring Harbor Symp. Quant. Biol. 50: 337 346.

Communicating editor: W. M. GELBART 